\title{
Research Paper: Prediction of Extramarital Relationships Based on Executive Functions With the Mediatory Role of Marital Commitment
}

\author{
Razieh Khorramabadi $^{1^{*}}$ (D), Zohreh Sepehri Shamloo' ${ }^{1}$ (D), Javad Salehi Fadardi ${ }^{1}$ Imanollah Bigdeli $^{1}$ (iD)
}

1. Department of Psychology, Faculty of Literature and Humanities, Persian Gulf University, Bushehr, Iran.

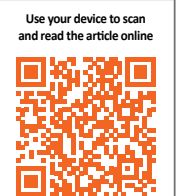

dfation: Khorramabadi, R., Sepehri Shamloo, Z., Salehi Fadardi, J., \& Bigdeli, I. (2019). Prediction of Extramarital Relationships Based on Executive Functions With the Mediatory Role of Marital Commitment. Journal of Practice in Clinical Psychology, 7(2), 147-157. http://dx.doi.org/10.32598/jpcp.7.2.147

http://dx.doi.org/10.32598/jpcp.7.2.147

(c) (i) (8)

Article info:

Received: 03 Nov 2018

Accepted: 08 Feb 2019

Available Online: 01 Apr 2019

Keywords:

Extramarital relationship, Infidelity, Affair, Executive functions, Executive control

\section{ABSTRACT}

Objective: The purpose of this study is to propound the structural model of executive functions and extramarital relationship with the mediating role of marital commitment.

Methods: The samples were selected by convenience sampling method. In experimental situation, for assessing the executive function of the participants did computerized exams, including Stroop test, Wisconsin test, Go-No-Go test, N-Back test, completed commitment questionnaire of Rusbult, and attitudes toward infidelity scale of Whatley. The obtained data were analyzed using regression and structural equation modeling.

Results: Executive functions, including inhibition, task switching, working memory, and commitment, directly affect the extramarital relationship through the mediation of commitment. The model has a suitable fit (average root mean square second approximation error; 0.051 , goodness of fit index; 0.942, normed fit index; 0.926, and comparative fit index; 0.942).

Conclusion: Executive functions (including inhibition, task switching, working memory), and marital commitment play an important role in extramarital relationships; therefore, they should be taken into consideration.

\section{* Corresponding Author:}

Razieh Khorramabadi, PhD

Address: Department of Psychology, Faculty of Literature and Humanities, Persian Gulf University, Bushehr, Iran.

Tel: +98 (773) 1222339

E-mail: rkhorramabadi@pgu.ac.ir 


\section{Highlights}

- Executive functions could predict extramarital relationships.

- Executive functions are directly associated with a tendency toward extramarital relationships.

- Marital commitment has a mediating role between executive functions and a tendency toward extramarital relationships.

- A tendency towards extramarital relationships increases with the decrease in executive functions.

\section{Plain Language Summary}

The extramarital affair is an emotional, sexual, or romantic involvement that violates the existing relationship's commitment norms. Research has shown that there are several factors, such as cognitive factors that are responsible for extramarital relationships. One of the cognitive factors is executive control. In this study, we investigated whether executive functions predict a tendency toward extramarital relationships. According to our study results, executive functions of inhibition, working memory, and flexibility are directly associated with a tendency toward extramarital relationships, and indirectly through the mediating role of marital commitment. Executive functions could predict extramarital relationships, and with the decrease in executive functions, a tendency towards extramarital relationships increases. Also, marital commitment has a negative relationship with extramarital relationships, so with a rise in marital commitment, a tendency toward extramarital relationships decreases.

\section{Introduction}

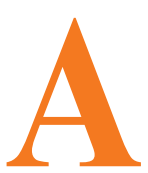

lthough long-term monogamous relationships could lead to reliable feeding (Rosenblatt \& Hillabrant, 1972), psychological studies have demonstrated that the maintenance of long-term relationships is not easily executed. For example, even romantically involved individuals find it difficult to ignore attractive alternatives (Maner, Gailliot, \& DeWall, 2007; Maner, Gailliot, \& Miller, 2009; Ueda, Yanagisawa, Ashida, \& Abe, 2018).

Among the various factors that threaten marital relationships, extramarital affairs have been increasingly considered by researchers. It has been identified as the most important factor for divorce in 160 different cultures (Fincham \& May, 2017). The definition of extramarital relationship is complex, and no single set of criteria is universally agreed upon (Blow \& Hartnett, 2005). Many behaviors might be considered unacceptable in the context of an intimate relationship, depending on cultural or social factors (Silva, Saraiva, Albuquerque, \& Arantes, 2017). The extramarital affair, which is an emotional, sexual, or romantic involvement that violates an existing relationship's commitment norms (Glass, 2002), can have damaging effects on both partners and their relationship (Weiser \& Weigel, 2017).
It is associated with poorer mental health particularly depression, anxiety, decreased personal and sexual confidence, losing self-esteem, and PTSD in noninvolvement partners (Bird, Butler, \& Fife, 2007; Gordon, Baucom, \& Snyder, 2004; Shrout \& Weigel, 2018). Infidelity occurs in many romantic relationships (Mark, Janssen, \& Milhausen, 2011), even in well-functioning relationships (where both partners are happy with each other and sexually satisfied) cheating can occur (Pronk \& Righetti, 2015)

Research has shown that there are several factors such as cognitive factors in the emergence of extramarital relationships (Khorramabadi, Sepehri, Salehi Fadardi \& Bigdeli, 2018; Pronk, Karremans, \& Wigboldus, 2011; Pronk \& Righetti, 2015; Ueda, Yanagisawa, Ashida, \& Abe, 2017; Ueda et al., 2018). One of the cognitive factors is executive control. Executive control or executive functions can be understood as the cognitive ability to change thoughts, feelings, and behaviors in a goaldirected manner. It can be assessed using a range of cognitive tasks that demand people to focus their attention on relevant information while inhibiting irrelevant one (Pronk et al., 2011).

Based on the research, executive control helps people to show efficient, goal-directed behavior in everyday life. For example, people with higher levels of executive control are more successful in refraining from eating $M \& M$ 
candies when they are on a diet (Hofmann, Schmeichel, \& Baddeley, 2012), or abstaining from aggressive behavior when they are provoked (Hofmann et al., 2012; Wilkowski, Robinson, \& Troop-Gordon, 2010). Recently, executive control has been related to a wide range of relationship maintenance processes such as forgiveness (Balliet, Li, \& Joireman, 2011; Burnette et al., 2014), refraining from aggression and intimate partner violence (Finkel, DeWall, Slotter, Oaten, \& Foshee, 2009), derogation of attractive alternatives (Ritter, Karremans, \& van Schie, 2010), remaining faithful (Ciarocco, Echevarria, \& Lewandowski, 2012; Meyer, Berkman, Karremans, \& Lieberman, 2011; Pronk \& Righetti, 2015), and finally engaging in some forms of sacrifice (Pronk \& Karremans, 2014). When interpreting these findings, it is essential to keep in mind that a high level of executive functions is not enough to show relationship-constructive behavior. Whether people act under relationship goals strongly depends on their level of motivation to protect their relationship. Only when people have the motivation and the ability, destructive impulses may transform into relationship-protective behavior (Pronk \& Righetti, 2015).

Various studies have examined and verified three domains of executive functions; inhibition, working memory, and flexibility about extramarital relations (Khorramabadi et al., 2018; Pronk \& Righetti, 2015). According to these studies, these three processes are needed for successful self-control. In situations where important goals are in conflict with immediate demands (e.g. conflict between having relationship with an attractive person outside of the marriage and marital commitment), inhibition seems necessary to prevent automatic behavioral tendency to the tempting stimulus, also a working memory to regulate emotion through attention control, and flexibility to manage multiple targets at the same time.
It should be noted that the executive functioning, described as the ability to regulate behavior, is not enough to show a good relationship behavior. To act per relationship goals, the people are strongly dependent on their motivational levels. The interesting thing about couple relationships is that when individuals are both "motivated" and "capable", destructive impulses can be transformed into a protective behavior (Pronk \& Karremans, 2014).

One of the principal motivating factors in marital life is commitment. The concept of marital commitment has drawn a lot of attention. It requires couples to value their marital relationships and have motivations to retain their marriage (Amato, 2006). Commitment is the main factor in maintaining marital relationships. Marital commitment is a sense of continuity found in attractions and limitations. It shows a person's dependence on a relationship, how to secure the person in a relationship, and how much the person feels that a long-term relationship is valuable (Nelson, Kirk, Ane, \& Serres 2011). Scholars believe that commitment increases marital stability. According to them, a relationship with higher commitment is more flexible, and the couples have more peace of mind and security (Mosako, 2009). Dean and Spanier (1974) argued that marital commitment was highly associated with marital adjustment (Mosako, 2009). By breaking the marriage covenant, the individual will face a traumatic phenomenon called "breach of marriage promise".

As it was mentioned, extramarital relationships have a destructive impact on individual and family and to prevent it, we need to identify the factors that affect it. Considering the role of executive functions (as a capacity factor) and marital commitment (as a motivation factor) in extramarital relationships, and lack of any model or a network of relations in this regard, this study aimed to formulate and test the structural model of executive functions and

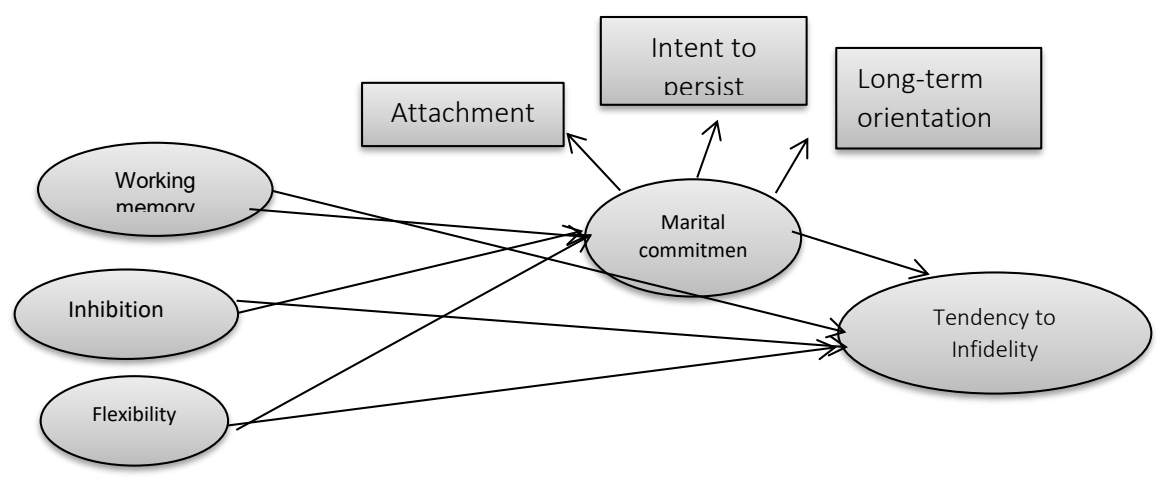

Figure 1. Initial conceptual model 
extramarital relations with the mediating role of marital commitment (Figure 1).

\section{Methods}

This research is a correlational study. The statistical population consisted of all married women and men in Bushehr City, Iran. According to the number of observed variables and assigning a coefficient of 15 for each variable, also taking into account the probability of having incomplete questionnaires, the sample size was estimated as 210 . Then the samples were selected using the convenience sampling technique and based on their willingness to participate in the study. In this regard, 210 married volunteers were recruited through call-ups in virtual social groups, print ads, telephone calls, and referral to places where they were available, such as real estate agencies. The process of study and the required period were explained to the participants. Then, they were asked to attend a laboratory environment (a room located in a consultation center having comfortable equipment and a computer with no distraction) at an appointed time.

To encourage the participants, some points were awarded, including participation in one workshop (of 3 workshops) and a cash prize (1000000 IRR) draw for two people at the end of the study. A recharge coupon was presented for those who came from a long distance. One of the volunteers was excluded due to color blindness. After the presence in the study location, four computerized tests were performed on the subjects. Before performing each test, they were given the necessary training, and the examiner left the room and returned after the completion of tests to avoid the distraction. Between the tests, there was a rest interval. When all tests were performed, the subjects were asked to complete the questionnaires. This process for each subject lasted from 45 minutes to one hour. The collected data were analyzed in SPSS (version 21) using descriptive statistics (Mean and SD) and correlation tests. For analyzing the study model, the Structural Equation Modeling (SEM) was performed in AMOS V. 21.

Wisconsin Card Sorting Test (WCST) was developed by (cited in Lezak, 2004). According to Cavallero et al. (2003), this test evaluates the abstract ability and shifting cognitive strategies in response to changing environmental feedback. It needs strategic planning, organized searching, and the ability to use environmental feedback to shift cognitive sets. The validity of this test for cognitive deficits after brain damage was higher than 0.86 , and its reliability in the Iranian population was reported as 0.85 . Moreover, its test-retest reliability is higher than 0.83 (Moradi, Jabari, Miraghayi, Parhoon, 2011).
In this study, we used a computer-based test. There were four key cards on top of the screen: one with a red triangle, one with two green stars, one with three yellow crosses, and the other card with four blue circles. Then, 60 response cards appeared in a completely random order, one by one at the bottom right corner of the screen, and the subject was asked to match the cards by clicking on one of the key cards. Immediately after the subject's response, the correct or incorrect feedback appears on the screen in the form of "true" and "false". The order of the four key cards was based on color, shape, and number. This test has been widely used to study abstract behaviors and cognitive flexibility. The most common indicators for measuring cognitive executive functions in the WCST are the number of responses and the number of repeated errors (Strauss \& Alesander, 2006)

$\mathrm{N}$-back Test is a working memory measurement method associated with executive functions. It was first introduced in 1985 by Kirchner. Coefficients of 0.54-0.84 show its high reliability (Madani et al., 2017). And as an indicator of working memory performance, it has acceptable validity. This test is widely used in neuropsychological interventions and studies. Since this test includes both maintaining and updating information, it is an appropriate tool for measuring working memory (Kane, Conway, Miura, \& Colflesh, 2007).

We prepared the Persian version of this computerized test. In this test, letters 1-9 randomly appear on the screen. The subject should compare the current letter with one letter (1-back task), two letters (2-back task), and three letters (3-back task) presented formerly to decide whether the appeared letters are identical to them. Performing this task requires remembering items for comparison purpose. In the current study, we used the 1-back condition, and the subjects were asked to compare each letter with the one item that appeared before. If they were identical, they should press the right key; otherwise, they had to press the left key. The number of correct responses and total reaction time of each subject was recorded by the system.

Classic Stroop Effect Test is one of the most widely used tests for selective attention, focused attention, and response inhibition. It is an experimental model and a basic test for the functioning of the frontal lobe. Stroop presented it in 1935 as a tool for studying information processing and its biases. In this test, the matched words (word color matches with its meaning) and unmatched words (word color does not match with its meaning) appear randomly at a given time, and then the Response Time (RT), number of correct responses, number of errors, and the interference score of the participants are recorded. 
The interference effect reduces the speed of the subjects in naming unmatched words compared to the matched words. In this test, the subjects have to respond to each of the four colored words by pressing one of the four specified keys based on their color and ignoring their meaning. In our study, this test was computerized using SuperLab V. 4 software. This test in our study was an indicator of inhibition. It has been used to measure cognitive inhibition in some studies (Mirdoraghi et al. 2012). The test-retest reliability of this test was examined by Lezak (2004) and reported as $0.80-0.91$.

Go-No-Go Test is widely used to measure inhibition. It includes two stimulus triggers: subjects must respond to one cue (Go) while inhibiting to respond to another cue (No-Go). Since the number of go triggers is usually greater than the no-go triggers, the readiness for responding in a person is greater. The absence of appropriate inhibition or committing error means performing a motor response when presenting a non-target stimulus. This test provides three separate scores; commission error rate, omission error rate, and reaction time.

In the study of Ghadiri et al. (2006) cited in (Mirdorgi et al. 2012), the reliability of this test was reported as 0.87 . In our study, this test was computerized using SuperLab V. 4 software. In this test, "go" stimulus was a geometric triangle that was presented among other geometric shapes (No-Go stimuli) in the middle of the 16-inch screen at a distance of $60 \mathrm{~cm}$ from the subject's eyes for $500 \mathrm{~ms}$. The subject should respond as soon as he saw the stimulus by pressing the space bar on the keyboard. After performing practice trials, 100 main attempts were presented, of which 70 were "Go" stimuli to generate a strong response. In the end, all responses and reaction time of the subjects were recorded.

Rusbult's Marital Commitment Scale was designed by Rusbult, Martz, and Agnew (1998) to measure the degree of commitment in marriage as a subscale of "investment model scale" presented by Rusbult et al. (1998). This questionnaire has 7 items with good reliability $(\alpha=0.90)$. Its 15-item version was developed by Rusbult et al. (2009) scored based on a 9-point Likert-type scale (from $0=$ completely disagree to $8=$ completely agree). It measures three subscales of intent to persist, attachment, and long-term orientation. We used the 15-item version. For this purpose, first, it was translated into Persian. Then it was back translated into English by one of the Psychology professors and then re-translated into Persian. Its predictive validity was tested and verified, and the internal consistency reliability for intent to persist, attachment, and long-term orientation scales were reported as $0.87,0.91$, and 0.73 , respectively.
Attitudes Toward Infidelity Scale was designed by Whatley (2008), this questionnaire examines an individual's belief in extramarital relationships. It has 12 items rated based on a 7-point Likert-type scale (from completely agree to completely disagree). Whatley reported its internal consistency as 0.80 . For its reliability, Boukam (2005) reported an alpha coefficient of 0.88 (Cited in Yiusefi, Karimi, and Aghayi, 2016); Abollahzadeh (2010) an alpha coefficient of 0.84; and Ajam (2016) an alpha coefficient of 0.89 (Cited in Yiusefi, Karimi, and Aghayi, 2016).

\section{Results}

Initially, the statistical assumptions were examined by Skewness, Kurtosis, and Kolmogorov-Smirnov tests and outliers were detected. Then by performing a Mahalanobis distance test, these outliers were deleted. Also, after examining the normality of data distribution, the measurement model of two study variables was analyzed and confirmed. Moreover, the results of Average Variance Extracted (AVE) showed that the values of all subscales of marital commitment and tendency to the extramarital relationship in the measurement model were greater than criterion value of 0.5 , which indicates that the model has a convergent validity. Furthermore, its Composite Reliability (CR) or structural reliability indicated that the values obtained from the components were higher than 0.07. Hence, AVE and CR of questionnaires are verified. Its theta reliability for marital commitment was obtained as 0.71 , and for a tendency toward extramarital relationships as 0.63.

Table 1 presents the correlations among all variables under study. In Table 2, the fit indicators are presented, and the result showed that the average root mean square second approximation error value equals to 0.051 , which is smaller than 0.1 and shows that mean errors of the model are appropriate, and the model is acceptable. Also, the Chi-squared value to the degree of freedom (2.66) is between 1 and 3. Also, the indexes of the goodness of fit index, comparative fit index, and normed fit index are also roughly equal or larger than 0.9 that show measurement model of the variables of the study is appropriate (Sadeghpour \& Moradi, 2011). According to Table 3, marital commitment and executive functions have a direct impact on the tendency to the extramarital relationship. In Table 4, the considered indirect paths were calculated according to standardized values $(\beta)$, indirect paths, active memory, flexibility, and inhibition based on the Bootstrap estimation method.

\section{Discussion}

This study was conducted to propound and test a model for explaining the tendency towards extramari- 


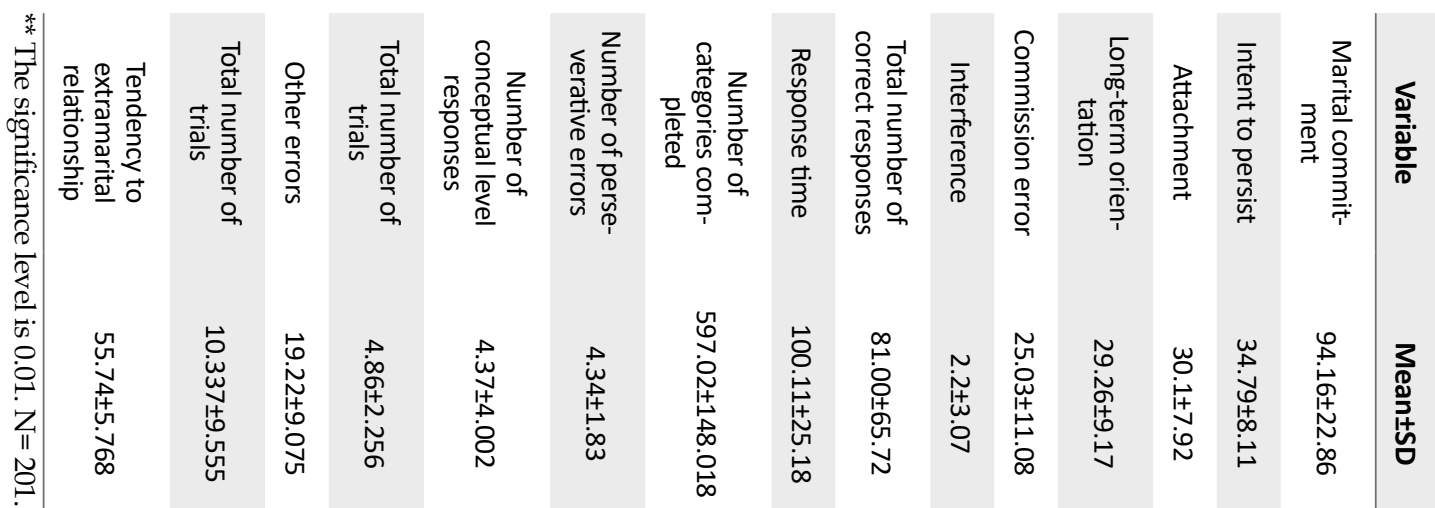

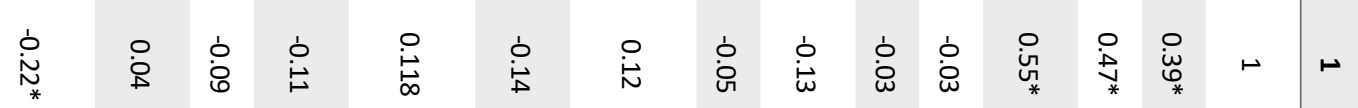

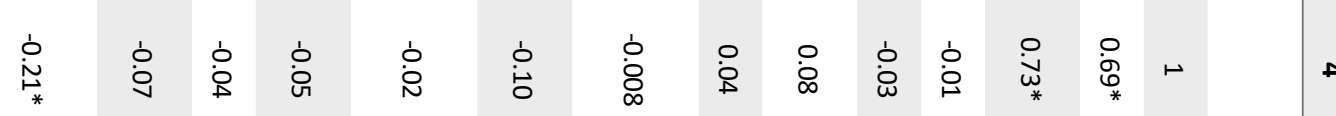

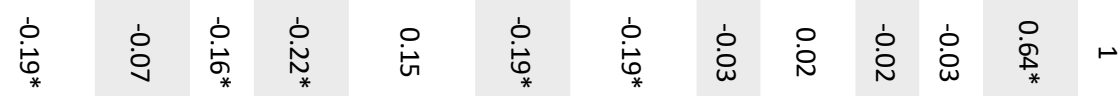

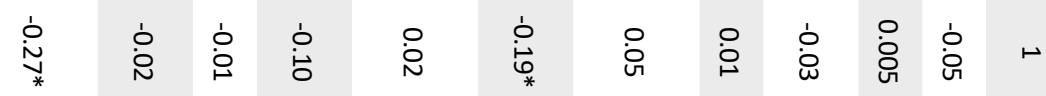

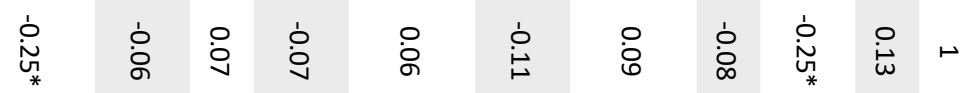

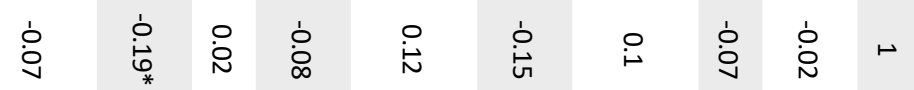

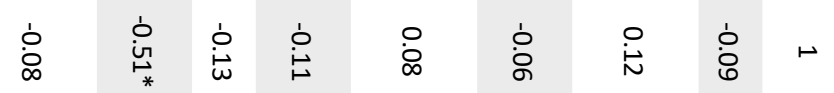

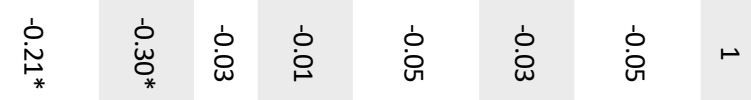

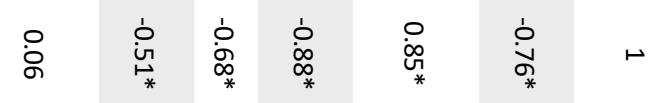

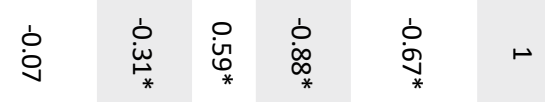

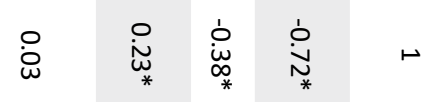

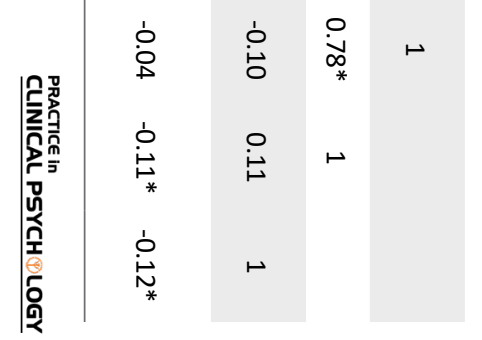


Table 2. Fit indicators derived from data and variables analysis

\begin{tabular}{|c|c|c|c|c|}
\hline \multirow{2}{*}{ Test Type } & \multirow{2}{*}{ Explanation } & \multirow{2}{*}{$\begin{array}{l}\text { Acceptable } \\
\text { Values }\end{array}$} & \multicolumn{2}{|c|}{ The Value Obtained } \\
\hline & & & Before the Correction & After Correction \\
\hline$X^{2} / d f$ & Relative Chi-square & $3>$ & 3.41 & 2.39 \\
\hline RMSEA & $\begin{array}{l}\text { Average root mean square second } \\
\text { approximation error }\end{array}$ & $0.1>$ & 0.056 & 0.051 \\
\hline GFI & Goodness of fit index & $0.9<$ & 0.912 & 0.942 \\
\hline $\mathrm{NFI}$ & Normed fit index & $0.9<$ & 0.866 & 0.926 \\
\hline $\mathrm{CFI}$ & Comparative fit index & $0.9<$ & 0.879 & 0.942 \\
\hline AGFI & Adjusted goodness of fit index & $0.9<$ & 0.901 & 0.921 \\
\hline TLI & Tucker-Lewis index & $0.9<$ & 0.894 & 0.927 \\
\hline RFI & Relative fit index & $0.9<$ & 0.867 & 0.915 \\
\hline PNFI & Parsimonious normed fit index & $\geq 0.5$ & 0.497 & 0.511 \\
\hline df & - & - & 79 & 75 \\
\hline
\end{tabular}

Table 3. Direct estimation of the model with Maximum Likelihood (ML)

\begin{tabular}{cccc}
\hline Variable & B & $\boldsymbol{\beta}$ & $\mathbf{R}^{2}$ \\
\hline Commitment on the tendency to extramarital relationship & -0.48 & -0.09 & 0.043 \\
\hline Working memory on the tendency to extramarital relationship & -0.11 & -0.16 & 0.017 \\
\hline Inhibition on the tendency to extramarital relationship & -0.66 & -0.13 & 0.085 \\
\hline Flexibility on the tendency to extramarital relationship & -0.11 & -0.13 & 0.014 \\
\hline
\end{tabular}

tal relationships. We also examined the relationship between executive functions and tendency to extramarital relationships by mediating role of marital commitment. Analysis of the model using the SEM method showed that the proposed model had a good fit after the correction of the initial model.
According to our study results, executive functions; i.e. inhibition, working memory, and flexibility were directly associated with a tendency toward extramarital relationships, and indirectly through the mediating role of marital commitment. Executive functions could predict extramarital relationships, and with the decrease in executive functions, a tendency towards extramarital relationships increases. This finding is consistent with the results of Ueda

Table 4. Indirect estimation of the model by using Bootstrap

\begin{tabular}{|c|c|c|c|c|}
\hline \multirow{2}{*}{ Variable } & \multirow{2}{*}{ B } & \multicolumn{2}{|c|}{ Limit } & \multirow{2}{*}{ Sig. } \\
\hline & & Lower & Upper & \\
\hline $\begin{array}{l}\text { Working memory on the tendency to extramarital relationship by } \\
\text { mediating marital commitment }\end{array}$ & -0.15 & -0.02 & 0.16 & 0.001 \\
\hline $\begin{array}{l}\text { Flexibility on the tendency to extramarital relationship by mediating } \\
\text { marital commitment }\end{array}$ & -0.11 & -0.03 & 0.13 & 0.001 \\
\hline $\begin{array}{l}\text { Inhibition on the tendency to extramarital relationship by mediating } \\
\text { marital commitment }\end{array}$ & -0.13 & -0.14 & 0.03 & 0.004 \\
\hline
\end{tabular}




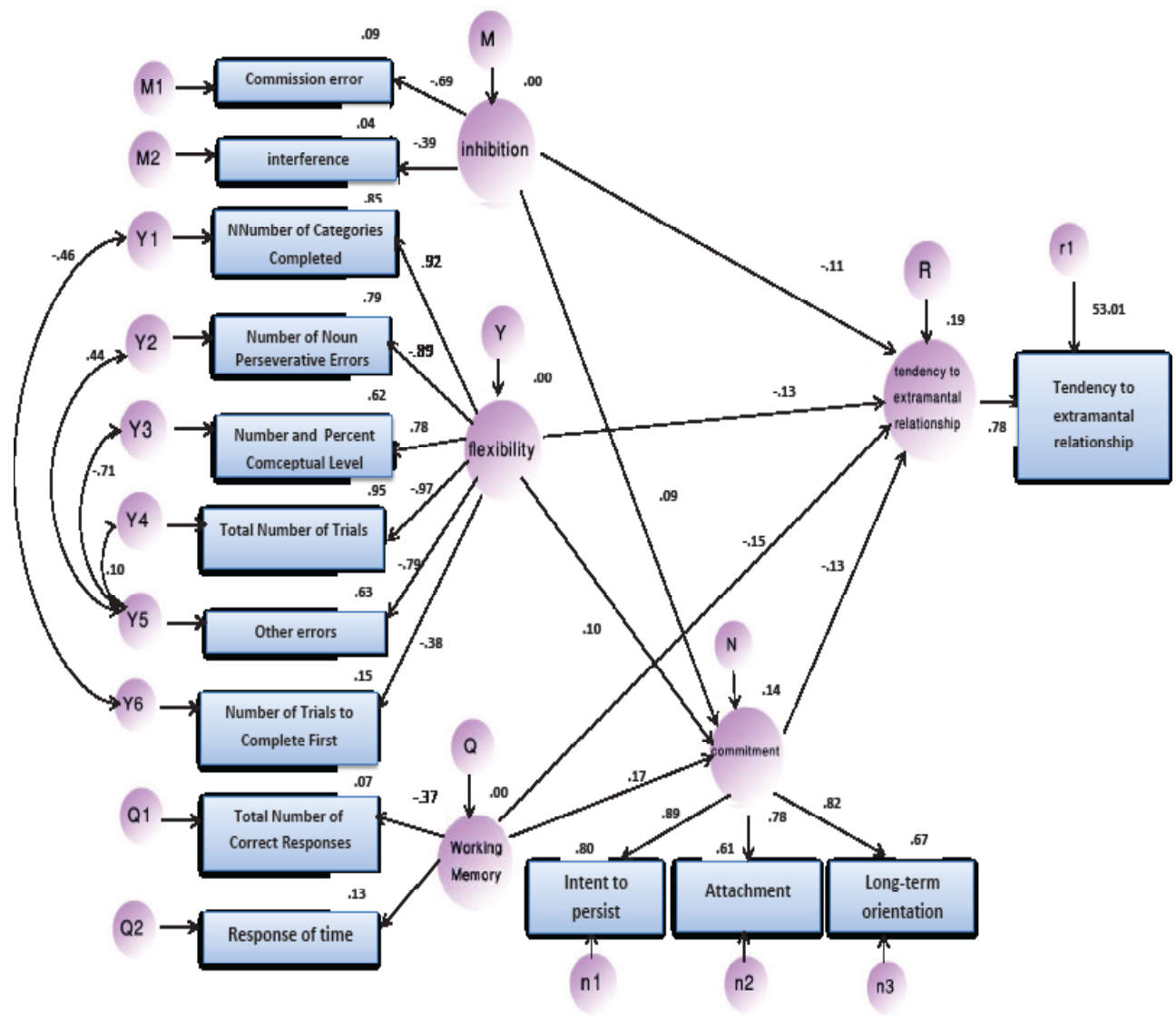

Figure 2. The structural model of executive functions and extramarital

et al. (2017) study. Hamburg and Pronk (2015), Pronk et al. (2011), and Ciarocco et al. (2012) showed that executive control had a relationship with the ability to remain faithful. Ritter et al. (2010) derogating attractive alternative with higher levels of executive control. Executive functions include a series of cognitive control processes that work together to regulate and form behaviors; they play an important role in guiding and controlling behavior. One of the primary goals in any marital relationship is retaining marriage. In every marriage, it is inevitable to face the destructive impulses that can disrupt or even ruin any relationship. Conflict is part of marital life and refers to any situation where the needs of wife overlap with the needs of husband and induce interpersonal conflicts, attractive alternatives, and different interests. Rusbult and Van Lange (2003) provided a model for behavioral transformation processes, according to which, when conflicts are created, individuals initially and automatically tend to behave along with their emotional impulses (i.e. impulsive responses), but acting on these impulses, depends on two moderating factors: motivation and capability. These factors are related to executive functions. That is, individuals can change their impulsive behavior when they are both motivated and capable.
This capability means high levels of executive control. In this way, they can transform their impulsive response to a response that is consistent with their overall and long-term goals. About marital relationships, it can also be argued that executive control induces a change in motivation by which individuals get away from self-interest impulses (e.g. attention or having an affair with a person out of marriage), and instead, respond to the interests of their spouses. When attention or affairs with an attractive person out of marriage conflicts with retaining marital life and commitment, inhibition prevents from automatic behavioral tendencies towards a tempting stimulus, while working memory adjusts emotion through attention control, and flexibility allows the individual to manage multiple simultaneous targets. All of these processes contribute to successful self-control (Wolff et al., 2016).

The results of this study show that commitment has a direct effect on the tendency towards extramarital relationships as well as a mediating role between executive functions and tendency towards extramarital affairs. That is, with a higher level of commitment, a tendency towards extramarital affairs decreases. Couples who have not mentally matured in their commitment to spouse and others 
have a double-minded behavior, leading to difficulty in marriage, which can often end in committing infidelity. Studies have shown that higher levels of marital commitment lead to high love expression (Finkel, Rusbult, Kumashiro, \& Hannon, 2002; Givertz, Segrin, \& Woszidlo, 2016), high level of forgiveness (Finkel et al., 2002; Molden \& Finkel, 2010), low conflicts, and low extramarital affairs (Mattingly et al., 2011).

Commitment, which is the cognitive component of love, is the orientation of a person to retain a long-term marital relationship and motivates the individual in this regard. It reduces the person's temptation for extramarital relationships and provides resources to enable individuals to shift their focus from short-term enjoyment to long-term enjoyment (Hadi et al., 2016). Therefore, people with high commitment most likely avoid committing infidelity, while those with lower commitment are more likely to be involved in it (Rodrigues, Lopes and Pereira, 2017; Hadi et al., 2016).

In sum, the main areas of executive functions (inhibition, flexibility, and active memory), as well as marital commitment, can explain some variations in the tendency towards extramarital affairs. The initial conceptual model of the study shows the effect of executive functions with the mediating role of marital commitment on the tendency towards extramarital relationships. These results can have both educational and therapeutic applications and be used in treatment and prevention protocols. It can also be the basis for future studies. In the present study, the tendency towards extramarital relationships was measured by a self-report questionnaire, which can increase the probability of bias. It is recommended that experimental studies be conducted to measure the model behaviorally. We also suggest examining the mediating role of other factors such as personality factors, including impulsivity or religious factors in studying the relationship between cognitive functions and extramarital relationships.

Based on the findings, it can be concluded that executive functions (including inhibition, task switching, working memory) and marital commitment play an important role in extramarital relationships. Marital commitment as a motivation factor can mediate the relation between executive functions and extramarital relationships; therefore, they should be taken into consideration.

\section{Ethical Considerations}

\section{Compliance with ethical guidelines}

All ethical principles were considered in this article. The participants were informed about the purpose of the research and its implementation stages; they were also assured about the confidentiality of their information; Moreover, They were allowed to leave the study whenever they wish, and if desired, the results of the research would be available to them.

\section{Funding}

This research did not receive any specific grant from funding agencies in the public, commercial, or not-forprofit sectors.

\section{Authors' contributions}

All authors contributed in designing, running, and writing all parts of the research.

\section{Conflict of interest}

The authors declared no conflict of interest.

\section{References}

Amato, P. R., \& Previti, D. (2003). People's reasons for divorcing: Gender, social class, the life course, and adjustment. Journal of Family Issues, 24(5), 602-26.

Balliet, D., Li, N. P., \& Joireman, J. (2011). Relating trait selfcontrol and forgiveness within prosocials and proselfs: Compensatory versus synergistic models. Journal of Personality and Social Psychology, 101(5), 1090-1105. [DOI:10.1037/a0024967] [PMID]

Bird, M. H., Butler, M. H., \& Fife, S. T. (2007). The process of couple healing following infidelity: A qualitative study. Journal of Couple E Relationship Therapy, 6(4), 1-25. [DOI:10.1300/ J398v06n04_01]

Blow, A. J., \& Hartnett, K. (2005). Infidelity in committed relati0nships ii: A substantive review. Journal of Marital and Family Therapy, 31(2), 217-33. [DOI:10.1111/j.1752-0606.2005. tb01555.x] [PMID]

Burnette, J. L., Davisson, E. K., Finkel, E. J., Van Tongeren, D. R., Hui, C. M., \& Hoyle, R. H. (2014). Self-control and forgiveness: A meta-analytic review. Social Psychological and Personality Science, 5(4), 443-50. [DOI:10.1177/1948550613502991]

Ciarocco, N. J., Echevarria, J., \& Lewandowski Jr, G. W. (2012). Hungry for love: The influence of self-regulation on infidelity. The Journal of Social Psychology, 152(1), 61-74. [DOI:10.1080/00 224545.2011.555435] [PMID]

Fincham, F. D., \& May, R. W. (2017). Infidelity in romantic relationships. Current Opinion in Psychology, 13, 70-4 [DOI:10.1016/j.copsyc.2016.03.008] [PMID]

Finkel, E. J., DeWall, C. N., Slotter, E. B., Oaten, M., \& Foshee, V. A. (2009). Self-regulatory failure and intimate partner vio- 
lence perpetration. Journal of Personality and Social Psychology 97(3), 483. [DOI:10.1037/a0015433] [PMID]

Finkel, E. J., Rusbult, C. E., Kumashiro, M., \& Hannon, P. A. (2002). Dealing with betrayal in close relationships: Does commitment promote forgiveness? Journal of Personality and Social Psychology, 82(6), 956-74. [DOI:10.1037//0022-3514.82.6.956] [PMID]

Givertz, M., Segrin, C., \& Woszidlo, A. (2016). Direct and indirect effects of commitment on interdependence and satisfaction in married couples. Journal of Family Psychology, 30(2), 214-20. [DOI:10.1037/fam0000174] [PMID]

Gordon, K. C., Baucom, D. H., \& Snyder, D. K. (2004). An integrative intervention for promoting recovery from extramarital affairs. Journal of Marital and Family Therapy, 30(2), 213-31. [DOI:10.1111/j.1752-0606.2004.tb01235.x] [PMID]

Hadi, S., Skandari, H., Sohrabi, F., Moetamedi, A. \& Farokhi, N. (2016). Structural models predict marital commitment based on attachment styles and mediator variables self-control and early maladaptive schemas (in people with emotional extramarital relations) (Persian)]. Journal of Counseling and Therapeutic Culture, 7(28), 33-60.

Hofmann, W., Schmeichel, B. J., \& Baddeley, A. D. (2012). Executive functions and self-regulation. Trends in Cognitive Sciences, 16(3), 174-180. [DOI:10.1016/j.tics.2012.01.006] [PMID]

Hamburg, M. E., \& Pronk, T. M. (2015). Believe you can and you will: The belief in high self-control decreases interest in attractive alternatives. Journal of Experimental Social Psychology, 56, 30-5.

Ghadiri, F., Jazayeri, A., Ashayeri, H., Ghazi Tabatabaei, M. (2006), The role of rehabilitation of cognitive in reduce deficits of executive function and symptoms of obsessive: Compulsive in Schizo-obsessive patients. Journal of Rehabilitation Medicine, 7(4), 15-24.

Glass, S. P. (2002). Couple therapy after the trauma of infidelity. New York: The Guilford Press

Kane, M. J., Conway, A. R., Miura, T. K., \& Colflesh, G. J. (2007). Working memory, attention control, and the N-back task: a question of construct validity. Journal of Experimental Psychology: Learning, Memory, and Cognition, 33(3), 615-22. [DOI:10.1037/0278-7393.33.3.615] [PMID]

Khorramabadi, R., Sepehri, Z., \& Bigdeli, I. (2018). [Structural model of executive function and extramarital relationship with mediating role of self-control (Persian)]. Journal of Cognitive Psychology, 6(1), 46-57.

Lezak, M. D., Howieson, D. B., Loring, D. W., \& Hannay, H. J. (2004). Neuropsychological Assessment, ( $4^{\text {th }}$ ed.). Oxford, UK: Oxford University Press.

Madani, s., Alizadeh, H., Farokhi, N. \& Hakimi Rad, E. (2017) [Development of an executive functions (response inhibition, updating,sustained attention) program and examining its effectiveness on symptoms amelioration in children with attention deficit/hyperactivity disorder (Persian)]. Quarterly of Psychology of Exceptional Individuals, 7(26), 1-25.

Maner, J. K., Gailliot, M. T., \& DeWall, C. N. (2007). Adaptive attentional attunement: Evidence for mating-related perceptual bias. Evolution and Human Behavior, 28(1), 28-36. [DOI:10.1016/j.evolhumbehav.2006.05.006]
Maner, J. K., Gailliot, M. T., \& Miller, S. L. (2009). The implicit cognition of relationship maintenance: Inattention to attractive alternatives. Journal of Experimental Social Psychology, 45(1), 174-9. [DOI:10.1016/j.jesp.2008.08.002]

Mark, K. P., Janssen, E., \& Milhausen, R. R. (2011). Infidelity in heterosexual couples: Demographic, interpersonal, and personality-related predictors of extradyadic sex. Archives of Sexual Behavior, 40(5), 971-82. [DOI:10.1007/s10508-0119771-z] [PMID]

Mattingly, B. A., Clark, E. M., Weidler, D. J., Bullock, M., Hackathorn, J., \& Blankmeyer, K. (2011). Sociosexual orientation, commitment, and infidelity: A mediation analysis. The Journal of Social Psychology, 151(3), 222-6. [DOI:10.1080/00224540903536162] [PMID]

Meyer, M. L., Berkman, E. T., Karremans, J. C., \& Lieberman, M. D. (2011). Incidental regulation of attraction: The neural basis of the derogation of attractive alternatives in romantic relationships. Cognition and Emotion, 25(3), 490-505. [DOI:10.1 080/02699931.2010.527494] [PMID] [PMCID]

Mirdoraghi, F., Ghanbary Hashemabady, B. A., Mashhadi, A. (2012). [Cognitive and behavioral inhibition in veterans withand without posttraumatic stress disorder (Persian)]. Iranian Journal of Military Medicine, 14(1), 41-7.

Moradi, A., Jabbari. H., Miraghayi. A., \& Parhon, H. (2011). [Executive Functions Performance among People with AIDS/ HIV (Persian)]. Journal of Modern Psychology, 6(24),15-24.

Mosako, J. (2009). Commitment and attachment dimensions. (Doctoral dissertation). West Lafayette, Indiana: Purdue University

Molden, D. C., \& Finkel, E. J. (2010). Motivations for promotion and prevention and the role of trust and commitment in interpersonal forgiveness. Journal of Experimental Social Psychology, 46(2), 255-68. [DOI:10.1016/j.jesp.2009.10.014]

Nelson, J. A., Kirk, A. M., Ane, P., \& Serres, S. A. (2011). Religious and spiritual values and moral commitment in marriage: Untapped resources in couples counseling? Journal of Counseling and Values, 55(3), 228-46.

Pronk, T. M., \& Karremans, J. C. (2014). Does executive control relate to sacrificial behavior during conflicts of interests? Personal Relationships, 21(1), 168-75. [DOI:10.1111/pere.12024]

Pronk, T. M., Karremans, J. C., \& Wigboldus, D. H. (2011). How can you resist? Executive control helps romantically involved individuals to stay faithful. Journal of Personality and Social Psychology, 100(5), 827-37. [DOI:10.1037/a0021993] [PMID]

Pronk, T. M., \& Righetti, F. (2015). How executive control promotes happy relationships and a well-balanced life Current Opinion in Psychology, 1, 14-7. [DOI:10.1016/j.copsyc.2014.11.016

Ritter, S. M., Karremans, J. C., \& van Schie, H. T. (2010). The role of self-regulation in derogating attractive alternatives. Journal of Experimental Social Psychology, 46(4), 631-7. [DOI:10.1016/j. jesp.2010.02.010]

Rodrigues, D., Lopes, D., \& Pereira, M. (2017). Sociosexuality, commitment, sexual infidelity, and perceptions of infidelity: Data from the second love web site. The Journal of Sex Research 54(2), 241-53. [DOI:10.1080/00224499.2016.1145182] [PMID] 
Rosenblatt, P. C., \& Hillabrant, W. J. (1972). Divorce for childlessness and the regulation of adultery. Journal of Sex Research, 8(2), 117-27. [DOI:10.1080/00224497209550737]

Rusbult, C. E., Martz, J. M., \& Agnew, C. R. (1998). The investment model scale: Measuring commitment level, satisfaction level, quality of alternatives, and investment size. Personal Relationships, 5(4), 357-87.

Rusbult, C. E., \& Van Lange, P. A. (2003). Interdependence, interaction, and relationships. Annual Review of Psychology, 54(1), 351-75.

Sadeghpour, B., Moradi, V. (2011). Statical analysis with Amos; amp \& Spss (Persian)]. Mazandaran: Mazandaran university.

Shrout, M. R., \& Weigel, D. J. (2018). Infidelity's aftermath: Appraisals, mental health, and health-compromising behaviors following a partner's infidelity. Journal of Social and Personal Relationships, 35(8), 1067-91. [DOI:10.1177/0265407517704091]

Silva, A., Saraiva, M., Albuquerque, P. B., \& Arantes, J. (2017). Relationship quality influences attitudes toward and perceptions of infidelity. Personal Relationships, 24(4), 718-28. [DOI:10.1111/pere.12205]

Struss, D. T., \& Alesander, M. P. (2006). Executive function and the frontal lobes: A conceptual view. Psychology Reaserch, 63(34), 289-98. [DOI:10.1007/s004269900007] [PMID]

Ueda, R., Yanagisawa, K., Ashida, H., \& Abe, N. (2017). Implicit attitudes and executive control interact to regulate interest in extra-pair relationships. Cognitive, Affective, \& Behavioral Neuroscience, 17(6), 1210-20. [DOI:10.3758/s13415-017-0543-7] [PMID]

Ueda, R., Yanagisawa, K., Ashida, H., \& Abe, N. (2018). Executive control and faithfulness: Only long-term romantic relationships require prefrontal control. Experimental Brain Research, 236(3), 821-8. [DOI:10.1007/s00221-018-5181-y] [PMID]

Weiser, D. A., \& Weigel, D. J. (2017). Exploring intergenerational patterns of infidelity. Personal Relationships, 24(4), 933-52. [DOI:10.1111/pere.12222]

Wilkowski, B. M., Robinson, M. D., \& Troop-Gordon, W. (2010). How does cognitive control reduce anger and aggression? The role of conflict monitoring and forgiveness processes. Journal of Personality and Social Psychology, 98(5), 830-40. [DOI:10.1037/a0018962] [PMID]

Wolff, M., Krönke, K. M., Venz, J., Kräplin, A., Bühringer, G., Smolka, M. N., et al. (2016). Action versus state orientation moderates the impact of executive functioning on reallife self-control. Journal of Experimental Psychology: General, 145(12), 1635-53. [DOI:10.1037/xge0000229] [PMID]

Yousefi, N., Karimipour, B. \& Amani, A. (2016). The study model of religious beliefs, conflict resolution styles, and marital commitment with attitudes toward marital infidelity. Journal of Applied Counseling, 6(1), 47-64. 